\title{
Information Support for Travel Agency Performance
}

\author{
https://doi.org/10.3991/ijes.v8i4.17669 \\ Anna Tarasova $\left.{ }^{(}\right)$, Anna Polukhina, Avdykerim Arnaberdiyev \\ Volga State University of Technology, Yoshkar-Ola, Russian Federation \\ tarasovaan@volgatech. net
}

\begin{abstract}
Internet technologies create new platforms for the sale of goods and services; however, their emergence arises new issues of how to attract and retain users. Modern Internet users enjoy freedom of choice, they can easily find travel services, or skip them just by closing the browser tab. That is how Customer Relationship Management (CRM) systems were introduced to build and manage efficiently good user relationships. This article discusses the main functions of CRM, according to the classification of The Center for Research on Information Technology and Organizations (the University of California, Irvine, USA) and considers the potentials of CRM systems on the market for large and small companies.
\end{abstract}

Keywords - Internet technologies, tourism service, custom relationship management, travel agency performance, online tour sales

\section{Introduction}

Tourism is an information-intensive activity. Services that tourism offers cannot be posed and considered as consumer or industrial goods. Travel services are bought in advance and away from the place of consumption. Therefore, tourism is almost entirely dependent on media resources (video, images, presentations), means of communication and information transfer. Information technologies are regarded a strategic development resource and a way to increase the competitiveness of travel companies (Morozova et al 2014). The development of the tourism industry is closely associated with the capabilities of the Internet. The network is abundant with thousands of representatives of tour operators, travel agencies, hotels, airlines, dozens of travel services booking systems (Law R., Leung K. and Wong R. 2004; Yunpeng L et al 2017 ). The Internet supplements the traditional channel of tourism services offtake with an electronic one. The digital economy changes the traditional pattern of economic relations between a provider and a consumer of tourism services: information production - tourism services. In such a scheme, information is a natural environment for the interaction of all the resources needed to create a tourist product; moreover, it is an independent resource that forms consumer preferences (Ziqi L and Xinping S 2017; $\mathrm{Li} \mathrm{H}$ and Suomi R 2007). Therefore, knowing the existing information services in tourism, the study of the main areas of application, the development of skills in the use of information technology is crucial for proper travel agency performance. In the 
context of modern globalization, public life is becoming more and more technologically advanced, new principles of information support and tourism management are being formed, which requires an understanding of the role of tourism information support as a subsystem of the information society.

The objective of our paper is to research information technologies that help to attract, retain and work with clients in travel agencies, as well as technologies that open up new platforms for the sale of tourism products, namely online sales. The article also investigates the impact the Internet technologies have on various industries, in particular on the tourism industry.

\section{Custom Relationship Management}

$21^{\text {st }}$ century demands that travel companies treat their potential and real customers in a different way. The client is respected, attracted, lured, and fought for. Each travel company in a market economy is trying new ways to grasp customer attention, looking for opportunities to provide additional services. Customer relationships are becoming a key factor in a company's success (Triznova M et al 2015; Rahimi R et al 2017). In the tourism business, a client is a travel agency for a tour operator and a tourist (an individual) for a travel agency.

Currently, the so-called operational CRM systems have gained the greatest development, allowing to receive maximum information about clients at the time of communication with them. The information gained and processed about the client (for example, his/her travel history, average budget, needs and preferences) is used to more accurately specify offers to a particular client, which are likely to be further accepted (Vogt C 2011). With a large number of customers, this approach cannot do without information technology as a backup tool. Hence, electronic Internet CRM systems, which are mainly focused on the increasing number of customers communicating with companies via the Internet are booming.

The Center for Research on Information Technology and Organizations (the University of California, Irvine, USA) classified the functionality that CRM should include:

- Contact management - Support for customer information and contact history, may include information on sales offices or the frequency of purchases / trips.

- Business management - A calendar and business diary.

- Communication management - An independent software module responsible for the transfer of information, its safety and replication.

- Forecasting - Provides information on long-term sales plans, as well as provides data from marketing research of company units.

- Opportunity management - Manages the motivating factors of attracts potential customers.

- Order management - Gathers information on travel products, places information in online booking.

- Documentation management - Development, implementation of standards for custom reports and advertising materials. 
- Sales analysis - Provides analytical capabilities to sales data.

- Product configuration - Storage of information about alternative options for tourism products and price characteristics.

- Marketing Encyclopedia - Provides updated information on products, prices, promotions, research results (for example, factors that influence the decision to purchase) and information on competitors.

Until recently, only giant travel companies or huge agent networks were interested in CRM systems, since the ever-increasing flow of communication and customer interactions became so enormous that it was practically impossible to process them all manually. However, we are now witnessing the change in the tendency (Jung-Chi P and Fu-Ming T 2011; Navío-Marco J et al 2018).

There are a number of large CRM systems on the market that are aimed specifically at solving the problem of communicating with customers in cases where there are a lot of such customers, and the number of calls to the company can amount to thousands during the day. However, the functionality of CRM systems for small and mediumsized businesses plays an even more important role. This is due to the fact that a high level of interaction and attentive attitude to customers are often the main factors that allow companies to successfully compete in the market with larger competitors; that is the strategy many smaller travel companies opt for.

On the gasp of the era of digitalization, the key players in customer support systems were Scopus, Vantive and Clarify. Nevertheless, the CRM sector did not remain indifferent to the trends. Scopus merged with Siebel in 1995, which currently has a strong lead in the global CRM systems market; Vantive was taken up by PeopleSoft in 1999, and Clarify went to Nortel the same year. The CRM-systems market has been divided between the leading players since 1998 - Siebel, Vantive, Clarify, Oracle and another 25 - 30 companies. Siebel has taken the lead with 1/3 of the CRM software market since 2000. Not so long ago, the well-known SAP company joined the struggle for the market to the already mentioned participants. Companies have launched new IT solutions based on their software development capabilities.

Analyzing the situation on the Russian tourism market, we should say that the main domestic developers of automation systems for travel companies MEGATEK and SAMO-Soft have the necessary functionality that can be positioned as a CRM system in the near future.

Thanks to a strategy that allows for meeting the requests of everyone who contacts the company, soon we can get an additional competitive advantage compared to large companies. Many of small companies have successfully thrived on the market for decades, despite the existence of giants that provide services of the same type and, possibly, cheaper. However, there is nothing more valuable to a person than a kind and careful attitude to his / her problems. Thus, small companies are more interested in gathering the most detailed and operational information about each client, as well as in providing the client with additional services that make communication with the company especially efficient. So, the introduction of modern CRM systems is crucial not only for large companies (as they need to process a large number of requests), but also for medium and even small enterprises. 
Let us consider the typical configuration and technical capabilities of a travel company implementing a CRM system. Such a company can have up to ten telephone lines, and a broadband Internet channel. A few years ago, the telephone was the main mode of interaction, today the Internet is catching up with telephone communications in terms of the number of calls received by the travel company via the Web site, and in many cases even exceeds the number of calls made to the company via telephone channels. Therefore, at the first stage, CRM systems should concentrate on these two channels of interaction with clients and be integrated with the Web site and with the telephone communication channel. In addition, one can consider the possibility of processing requests received by e-mail and fax.

The main goal of the CRM-system is to get the most complete information on the customer for the best service. If a potential client goes to the company's website and dives deep enough into the site's information tree, then such a call is regarded by the system as noteworthy and a message about this client is sent to the workplace of an expert working in the office of a travel company. If this contact comes from a computer that was previously registered on the site, then this message is sent to a specific employee of the company who previously worked with this client. In the case of the first visit, the information is transmitted according to the best choice method, that is, to the expert who most deeply knows this area and the product that the client is interested in. Then everything happens the same way as in the electronic store. The customer is given the opportunity to place an order electronically. In addition, he can request a system for organizing an automatic telephone connection with an expert and discuss all the details of the tourist product that interests him/her. If a client called the company by phone, the system recognizes the caller by number and subsequently forwards the call directly to the expert who works with this category of tourism product or with this client and actually performs the functions of a Call center.

Here is a good example of a CRM system. A client calls the travel company, an operator sees on a computer screen all information about the caller, including the previous trips made, the birthdays of his/her family members, which helps the operator quickly find out why the client is calling and make him/her an 'offer that is hard to refuse'. For example, the operator would speak about new products or special offers. With such forethought clients tend to stay with travel agency longer and keep to the existing ties.

The basis for the success of any CRM system is the storage of all information about customer interactions in one place, in a single database. The more the CRM system is used, the more efficiently it works, the deeper analytical dependencies and relationships can be identified in the information accumulated during its operation.

One of the main issues in creating and maintaining such a relationship system is the task of maintaining the integrity and security of customer information. Any company striving for a more effective interaction with its clients to collect the maximum information about them, should take care of the non-dissemination of these data. Customer trust is worth a lot. The issue of collecting private information is not such a trifle as it might seem at first glance. Clients may have their own opinion on providing the facts about their biography. There is still no consensus on what information can be used for business purposes, and which is unacceptable to use, even if the client has 
provided access to it. The basic procedures required of a company to protect private client information include:

1. Notification of the client about the purposes of collecting information about him/her and its subsequent usage.

2. The client may refuse to build relationships with the company, however, that should not decrease his/her value for the company in case of a long-term and fruitful interaction.

3. The client should be given the opportunity to view information about him/her and adjust information that is not related to the internal procedures of the company (rating system, comments of contact persons, etc.).

4. It is essential to protect the access of unauthorized persons to private information.

5. Measures to protect private information about the client increase the level of trust between the company and its clientele.

The CRM implementation process will require continued efforts by the IT department. CRM is a continuous process; therefore, IT department employees should be prepared for constant system maintenance and direct their efforts towards ensuring the smooth functioning of software applications and data structures.

\section{Online Tour Sales}

More and more tourists buy various tourism products and services on the Internet. They tend to buy not just airline tickets or 'simple' mass tours. The market for online sales of tourism products in Russia is booming by about a third every year. If in 2016 the market for online sales of tourism products and services increased to 640 billion rubles against 530 billion a year earlier, then in 2017 the growth was already up to 780 billion rubles (Figure 1). The tendency can be applied to airline tickets, tours, and online sales of excursions and tickets for events in Moscow and in the regions. Small and medium-sized enterprises selling tours and excursions in Russia need to create their own online sales channel in order to expand their target audience. This can give a high conversion of traffic to real sales under certain circumstances. 


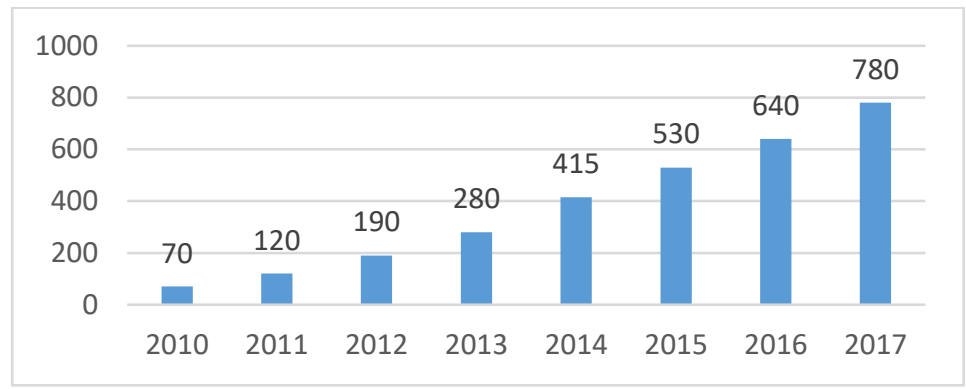

Fig. 1. Online sales of travel services by Russian customers, billion rubles

Source: Data Insight

To start online sales of domestic tourism products a travel company needs the following:

- A tour product with a good description and visual presentation.

- A website: an updated website with new functionality, a section on the site, a landing page or a page on social networks.

- Software: a company might need to develop or purchase and implement ready-made software for direct sales on the website.

- To implement a step-by-step plan for the transition to a new sales model.

Entering the online sales market is a complex and costly process for small and medium-sized travel companies: all of the above require extremely scarce resources. Small companies are hindered, firstly, by the lack of competent specialists: there are no people who can not only use modern marketing tools, but also transfer these competencies into software functionality. Secondly, there is a lack of time for all these 'non-core' work - most employees are busy with a daily routine, with the purpose of keeping the company afloat. Thirdly, these companies need large start-up investments.

However, small and medium-sized travel companies can use ready-made cloud solutions that can be easily and quickly integrated into an existing business if they truly want to start online sales. This is a ready-made tool that will reduce the time for working with tourists and reduce additional development costs, therefore, such services will cost several times cheaper than creating your own software. The value of such cloud services is that they help quickly set up a company's work online with minimal efforts. Additionally, the service interface is so simple that it will make online marketing accessible to any company manager. Modern software for managing sales of tours and excursions online will allow tourists to independently go through all stages of the purchase: to find an offer according to the essential parameters, place an order, pay online, and receive a ticket and a check by e-mail. A cloud service is a per se business automation that will help get away from the daily routine and free up resources for the development of the company on the network.

Before launching online sales, you need to know two basic laws. The first is Federal Law -152 dated July 27, 2006 'On Personal Data'. According to it, a company should obtain consent to collect and process tourist data. The second law is FZ-54 dated May 
22, 2003 'On the use of cash-register equipment accounting in the Russian Federation'. According to this Federal Law, a travel company needs to use new-style cash-register equipment that is connected to the Internet and sends data to the Fiscal Data Operator and Tax Services. A buyer should receive a check with a QR code on his/her e-mail or an SMS. When making a payment for the product online, a fiscal receipt should also be sent to the buyer. In the case of a ready-made cloud solution, all requirements are already prescribed in the software. You can do without buying a cash-register equipment. In this case, you sign a contract with a payment agent that will report to Tax Authorities. This option of maintaining financial documents will avoid additional costs for cash registers. Besides, reporting to the tax on online payments will totally paying agent's responsibility, and you will only develop your online resource.

\section{Conclusion}

Information technology can significantly improve the quality of interaction of a travel company with a client, affect the management functions and build relationships between them. There is nothing unusual in the idea of improving the interaction of a company with a client, but today, with the rapid development of information technologies, it has acquired a new face, a new name and a new development, since modern technologies allow for implementing it at a different level of functionality using integrated CRM systems (Ukpabi D C and Karjaluoto H 2017). The CRM system will start collecting market information needed by the travel company from the moment it is introduced, and the sooner the company begins to use it, the sooner it begins to receive detailed information on the market, its needs and trends on a daily basis. Unlike any research commissioned or held by company employees, this will be real information on which customers are interested in what products, and it will allow not only to accurately plan sales volumes, but also to catch market changes in time, which will influence the forthcoming customer needs.

Owners of travel companies who will not ignore the growth factor of the e-travel market, those who can adapt their website or social networks to the trends of independent shopping by tourists, will be in demand by a new generation of customers who prefer to make most purchases online.

\section{$5 \quad$ References}

[1] Morozova N S, Morozov M A, Chudnovsky A D, Zhukova M A, Rodigin L A 2014 Information Support of Tourism Moscow 288.

[2] Law R, Leung K and Wong R (2004), "The impact of the Internet on travel agencies", International Journal of Contemporary Hospitality Management, Vol. 16 No. 2, 100-107. https://doi.org/10.1108/09596110410519982

[3] Yunpeng L, Clark H, Chao H, Liqiong D, The concept of smart tourism in the context of tourism information services, Tourism Management, Vol. 58, 2017, 293-300, https://doi.org/10.1016/j.tourman.2016.03.014 
[4] Ziqi L, Xinping S, Web functionality, web content, information security, and online tourism service continuance, Journal of Retailing and Consumer Services, Vol. 39, 2017, 258-263, https://doi.org/10.1016/j.jretconser.2017.06.003

[5] Li H, Suomi R (2007) Customer's Perceptions and Intentions on Online Travel Service Delivery: An Empirical Study in China. In: Wang W., Li Y., Duan Z., Yan L., Li H., Yang $X$. (eds) Integration and Innovation Orient to E-Society Volume 2. IFIP International Federation for Information Processing, vol 252. Springer, Boston, MA https://doi.org/10.1007/978-0-387-75494-9_15

[6] Triznova M, Matova H, Dvoracek J, Sadek S, Customer Relationship Management Based on Employees and Corporate Culture, Procedia Economics and Finance, Vol. 26, 2015, 953 959, ISSN 2212-5671, https://doi.org/10.1016/s2212-5671(15)00914-4

[7] Rahimi R, Köseoglu M, Ersoy A and Okumus F (2017), "Customer relationship management research in tourism and hospitality: a state-of-the-art", Tourism Review, Vol. 72 No. 2, 209220. https://doi.org/10.1108/tr-01-2017-0011

[8] Vogt C A (2011). Customer Relationship Management in Tourism: Management Needs and Research Applications. Journal of Travel Research, 50(4), 356-364. https://doi.org/10. $1177 / 0047287510368140$

[9] Jung-Chi P, Fu-Ming T, The acceptance and use of customer relationship management (CRM) systems: An empirical study of distribution service industry in Taiwan, Expert Systems with Applications, Vol. 38, Issue 1, 2011, 579-584, https://doi.org/10. 1016/j.eswa.2010.07.005

[10] Navío-Marco J, Ruiz-Gómez L M, Sevilla-Sevilla C, Progress in information technology and tourism management: 30 years on and 20 years after the internet - Revisiting Buhalis \& Law's landmark study about e-Tourism, Tourism Management, Vol. 69, 2018, 460-470, https://doi.org/10.1016/j.tourman.2018.06.002

[11] Ukpabi D C, Karjaluoto H, Consumers' acceptance of information and communications technology in tourism: A review, Telematics and Informatics, Volume 34, Issue 5, 2017, 618-644, https://doi.org/10.1016/j.tele.2016.12.002

\section{Authors}

Anna Tarasova is a professor in the Department of Foreign Languages at Volga State University of Technology, Yoshkar-Ola, Mari El Republic, Russian Federation. Email: tarasovaan@volgatech.net

Anna Polukhina is a professor in the Department of Service \& Tourism at Volga State University of Technology, Yoshkar-Ola, Mari El Republic, Russian Federation

Avdykerim Arnaberdiyev is a professor at Volga State University of Technology, Yoshkar-Ola, Mari El Republic, Russian Federation.

Article submitted 2020-08-10. Resubmitted 2020-10-12. Final acceptance 2020-10-13. Final version published as submitted by the authors. 